\title{
Non-Hematologic Malignancy
}

National Cancer Institute

\section{Source}

National Cancer Institute. Non-Hematologic Malignancy. NCI Thesaurus. Code C9226.

A malignant neoplasm that arises from a site other than the bone marrow and lymphoid tissue. 